\title{
Analysis of the Connections between Modules in the EB
}

\author{
By \\ V. Guarino
}

Argonne National Laboratory

High Energy Physics Division

Argonne, IL 60439

May 16, 2002

*Work supported in part by the U.S. Department of Energy, Division of High Energy Physics, under Contract W-31-109-ENG-38. 
Argonne National Laboratory, with facilities in the states of Illinois and Idaho, is owned by the United States Government and operated by The University of Chicago under the provisions of a contract with the Department of Energy.

\footnotetext{
This report was prepared as an account of work sponsored by an agency of the United States Government. Neither the United States Government nor any agency thereof, nor The University of Chicago, nor any of their employees or officers, makes any warranty, express or implied, or assumes any legal liability or responsibility for the accuracy, completeness, or usefulness of any information, apparatus, product, or process disclosed, or represents that its use would not infringe privately owned rights. Reference herein to any specific commercial product, process, or service by trade name, trademark, manufacturer, or otherwise, does not necessarily constitute or imply its endorsement, recommendation, or favoring by the United States Government or any agency thereof. The views and opinions of document authors expressed herein do not necessarily state or reflect those of the United States Government or any agency thereof, Argonne National Laboratory, or The University of Chicago.
}

Available electronically at http://www.doe.gov/bridge

Available for a processing fee to U.S. Department of Energy and its contractors, in paper, from:

U.S. Department of Energy

Office of Scientific and Technical Information

P.O. Box 62

Oak Ridge, TN 37831-0062

phone: (865) 576-8401

fax: (865) 576-5728

email: reports@adonis.osti.gov 


\title{
Analysis of the Connections between Modules in the EB
}

\author{
By \\ V. Guarino \\ Argonne National Laboratory \\ High Energy Physics Division \\ Argonne, IL 60439
}

May 16, 2002

*Work supported in part by the U.S. Department of Energy, Division of High Energy Physics, under Contract W-31-109-ENG-38. 


\title{
Analysis of the Connections between Modules in the EB
}

\author{
Victor Guarino \\ Argonne National Laboratory \\ May 16, 2002
}

\section{Introduction}

Over the last several years, calculations have been performed to find the forces that are acting between modules and on the support saddles in the EB. This paper examines these forces and calculates the stresses in the connections between modules. In the Tile Calorimeter, the modules are only connected at three points. First, at the inner radius there is a bearing connection to support the force in the phi direction. Second, at the outer radius there is a bearing connection in the phi direction and, finally, there is a bolted connection designed to withstand the radial load. Each of these connections will be examined separately.

\section{FEA Model}

An extensive three-dimensional FEA model was created, which modeled the connections between modules, the girder, submodules and the connection to the girder, the connections between the modules and the support saddles, and the support saddles. Out of this analysis, the forces between modules have been extracted. Details of this analysis can be found in ANL Technical Report \# ANL-HEP-TR-01-097, "Extended Barrel Support Saddle Design and Analysis". The largest forces between modules were found in load case C4 which had the following characteristics:

- The weight of the EB and cryostat was increased by $35 \%$ per Eurocode.

- A seismic load in the X- and Z-direction of .15g was applied.

- The magnetic load was applied and increased by $35 \%$ per Eurocode.

- The EB was supported on the hydraulic jacks.

- Module \#'s begin at 1 at the 6 o'clock position and move counterclockwise

\section{Forces Between Modules}

The forces between modules are listed below for the front, middle, and back of the EB for the load case described above. Force P1 is the bearing force at the inner radius, force P2 is the bearing force at the outer radius, and force $\mathrm{Pt}$ is the radial force at the outer radius. The modules are numbered so that when the EB is viewed from the IP, module \#1 is at the bottom (6 o'clock position) and the module \#'s move in a counter clockwise direction, i.e. module 32 is at 3 o'clock. 


\begin{tabular}{|c|c|c|c|}
\hline \multicolumn{4}{|c|}{ Forces at the Front $(\mathrm{N} / \mathrm{mm})$} \\
\hline Module & & & \\
\hline \# & P1 & $\mathbf{P 2}$ & Pt \\
\hline 2 & 680.00 & 1340.00 & -350.00 \\
\hline 3 & 705.00 & 1360.00 & -362.00 \\
\hline 4 & 761.00 & 1420.00 & -396.00 \\
\hline 5 & 865.00 & 1570.00 & -403.00 \\
\hline 6 & 1110.00 & 1640.00 & 488.00 \\
\hline 7 & 1450.00 & -2540.00 & -171.00 \\
\hline 8 & 1760.00 & -2020.00 & 780.00 \\
\hline 9 & 1910.00 & -1550.00 & 1240.00 \\
\hline 10 & 2190.00 & -1160.00 & 1610.00 \\
\hline 11 & 2620.00 & -847.00 & 1670.00 \\
\hline 12 & 783.00 & -623.00 & 748.00 \\
\hline 13 & 975.00 & -429.00 & 560.00 \\
\hline 14 & 1110.00 & -274.00 & 391.00 \\
\hline 15 & 1180.00 & -148.00 & 208.00 \\
\hline 16 & 1190.00 & -45.90 & 76.00 \\
\hline 17 & 1160.00 & 38.50 & -43.80 \\
\hline 18 & 1110.00 & 108.00 & -147.00 \\
\hline 19 & 1030.00 & 165.00 & -246.00 \\
\hline 20 & 934.00 & 210.00 & -348.00 \\
\hline 21 & 818.00 & 245.00 & -408.00 \\
\hline 22 & 696.00 & 273.00 & -448.00 \\
\hline 23 & 567.00 & 295.00 & -497.00 \\
\hline 24 & 437.00 & 313.00 & -493.00 \\
\hline 25 & 318.00 & 329.00 & -477.00 \\
\hline 26 & 215.00 & 347.00 & -446.00 \\
\hline 27 & 129.00 & 366.00 & -415.00 \\
\hline 28 & 59.60 & 388.00 & -392.00 \\
\hline 29 & 11.20 & 414.00 & -335.00 \\
\hline 30 & 0.00 & 448.00 & -267.00 \\
\hline 31 & 0.00 & 493.00 & -218.00 \\
\hline 32 & 0.00 & 549.00 & -129.00 \\
\hline 33 & 0.00 & 597.00 & -38.70 \\
\hline 34 & 0.00 & 597.00 & 52.10 \\
\hline 35 & 0.00 & 564.00 & 127.00 \\
\hline 36 & 0.00 & 504.00 & 178.00 \\
\hline 37 & 0.00 & 450.00 & 248.00 \\
\hline 38 & 2.30 & 406.00 & 312.00 \\
\hline 39 & 31.60 & 370.00 & 341.00 \\
\hline 40 & 84.50 & 339.00 & 395.00 \\
\hline
\end{tabular}




\begin{tabular}{cccc}
41 & 164.00 & 312.00 & 433.00 \\
42 & 261.00 & 287.00 & 457.00 \\
43 & 371.00 & 261.00 & 453.00 \\
44 & 479.00 & 231.00 & 412.00 \\
45 & 581.00 & 196.00 & 379.00 \\
46 & 678.00 & 153.00 & 331.00 \\
47 & 757.00 & 102.00 & 239.00 \\
48 & 810.00 & 37.00 & 166.00 \\
49 & 836.00 & -41.70 & 73.10 \\
50 & 816.00 & -137.00 & -50.90 \\
51 & 727.00 & -258.00 & -190.00 \\
52 & 548.00 & -412.00 & -369.00 \\
53 & 2680.00 & -647.00 & -1060.00 \\
54 & 2260.00 & -804.00 & -849.00 \\
55 & 1980.00 & -931.00 & -110.00 \\
56 & 1830.00 & -1160.00 & 456.00 \\
57 & 1710.00 & -1610.00 & -21.70 \\
\hline 58 & 1490.00 & 2520.00 & -438.00 \\
59 & 1250.00 & 2330.00 & -376.00 \\
60 & 1070.00 & 2020.00 & -384.00 \\
61 & 936.00 & 1800.00 & -371.00 \\
62 & 839.00 & 1620.00 & -360.00 \\
63 & 767.00 & 1500.00 & -378.00 \\
64 & 712.00 & 1420.00 & -363.00
\end{tabular}

\begin{tabular}{|c|c|c|c|}
\hline \multicolumn{4}{|c|}{ Force at the Middle (N/mm) } \\
\hline $\begin{array}{c}\text { Module } \\
\text { \# }\end{array}$ & P1 & P2 & Pt \\
\hline 2 & 354.00 & 948.00 & -247.00 \\
3 & 281.00 & 882.00 & -257.00 \\
4 & 199.00 & 785.00 & -281.00 \\
5 & 110.00 & 620.00 & -269.00 \\
6 & 37.80 & 184.00 & -16.50 \\
7 & 0.00 & -346.00 & -3.90 \\
8 & 0.00 & -434.00 & 413.00 \\
9 & 28.60 & -409.00 & 706.00 \\
10 & 186.00 & -317.00 & 917.00 \\
11 & 364.00 & -203.00 & 907.00 \\
12 & 522.00 & -110.00 & 596.00 \\
13 & 624.00 & -36.90 & 485.00 \\
14 & 697.00 & 29.40 & 378.00 \\
\hline
\end{tabular}




\begin{tabular}{lccc}
15 & 744.00 & 85.10 & 249.00 \\
16 & 766.00 & 130.00 & 169.00 \\
17 & 772.00 & 167.00 & 91.70 \\
18 & 763.00 & 196.00 & 23.00 \\
19 & 740.00 & 219.00 & -52.00 \\
20 & 702.00 & 231.00 & -136.00 \\
21 & 652.00 & 235.00 & -182.00 \\
22 & 594.00 & 234.00 & -217.00 \\
23 & 528.00 & 227.00 & -269.00 \\
24 & 457.00 & 215.00 & -269.00 \\
25 & 387.00 & 203.00 & -263.00 \\
26 & 318.00 & 191.00 & -248.00 \\
27 & 251.00 & 180.00 & -241.00 \\
28 & 185.00 & 166.00 & -245.00 \\
29 & 122.00 & 152.00 & -213.00 \\
30 & 65.50 & 140.00 & -178.00 \\
31 & 8.25 & 130.00 & -164.00 \\
32 & 0.00 & 120.00 & -105.00 \\
33 & 0.00 & 116.00 & -49.20 \\
34 & 0.00 & 117.00 & 6.47 \\
35 & 0.00 & 119.00 & 45.50 \\
36 & 0.00 & 123.00 & 62.80 \\
37 & 33.70 & 127.00 & 105.00 \\
38 & 72.30 & 135.00 & 142.00 \\
39 & 120.00 & 142.00 & 146.00 \\
40 & 173.00 & 148.00 & 184.00 \\
41 & 234.00 & 156.00 & 209.00 \\
42 & 299.00 & 164.00 & 225.00 \\
43 & 366.00 & 172.00 & 216.00 \\
44 & 430.00 & 175.00 & 176.00 \\
45 & 489.00 & 171.00 & 155.00 \\
46 & 546.00 & 164.00 & 123.00 \\
47 & 595.00 & 149.00 & 52.20 \\
48 & 636.00 & 127.00 & 12.90 \\
49 & 670.00 & 99.40 & -41.70 \\
50 & 692.00 & 67.40 & -120.00 \\
51 & 699.00 & 26.90 & -208.00 \\
52 & 683.00 & -20.30 & -324.00 \\
53 & 619.00 & -89.80 & -503.00 \\
54 & 567.00 & -128.00 & -294.00 \\
\hline 5 & 554.00 & -107.00 & -94.50 \\
57 & 613.00 & 98.50 & -15.60
\end{tabular}


Forces at the Back (N/mm)

Module

$\begin{array}{llcl}58 & 633.00 & 510.00 & -111.00 \\ 59 & 637.00 & 947.00 & -155.00 \\ 60 & 627.00 & 1040.00 & -189.00 \\ 61 & 605.00 & 1080.00 & -196.00 \\ 62 & 574.00 & 1080.00 & -208.00 \\ 63 & 532.00 & 1070.00 & -248.00 \\ 64 & 479.00 & 1040.00 & -246.00\end{array}$

$\begin{array}{cccc}\# & \mathbf{P 1} & \mathbf{P 2} & \mathbf{P t} \\ 2 & 390.00 & 744.00 & -127.00 \\ 3 & 309.00 & 791.00 & -144.00 \\ 4 & 212.00 & 863.00 & -169.00 \\ 5 & 100.00 & 951.00 & -161.00 \\ 6 & 2.92 & 933.00 & -236.00 \\ 7 & 0.00 & 241.00 & -240.00 \\ 8 & 0.00 & 195.00 & -326.00 \\ 9 & 0.00 & 150.00 & -362.00 \\ 10 & 18.50 & 166.00 & -149.00 \\ 11 & 125.00 & 198.00 & 45.90 \\ 12 & 278.00 & 224.00 & 378.00 \\ 13 & 367.00 & 224.00 & 353.00 \\ 14 & 447.00 & 224.00 & 321.00 \\ 15 & 513.00 & 225.00 & 264.00 \\ 16 & 563.00 & 222.00 & 242.00 \\ 17 & 605.00 & 218.00 & 217.00 \\ 18 & 638.00 & 210.00 & 191.00 \\ 19 & 658.00 & 198.00 & 150.00 \\ 20 & 662.00 & 184.00 & 94.50 \\ 21 & 650.00 & 164.00 & 66.70 \\ 22 & 630.00 & 140.00 & 39.50 \\ 23 & 598.00 & 114.00 & -6.49 \\ 24 & 557.00 & 83.70 & -12.60 \\ 25 & 516.00 & 51.20 & -17.90 \\ 26 & 476.00 & 15.70 & -22.10 \\ 27 & 435.00 & -23.30 & -38.20 \\ 28 & 388.00 & -64.30 & -66.90 \\ 29 & 337.00 & -111.00 & -67.80 \\ 30 & 290.00 & -165.00 & -68.20 \\ 31 & 242.00 & -224.00 & -88.40\end{array}$


$11 / 07 / 2002$

$\begin{array}{lccc}32 & 158.00 & -293.00 & -70.30 \\ 33 & 15.60 & -350.00 & -54.20 \\ 34 & 0.00 & -351.00 & -40.70 \\ 35 & 61.70 & -318.00 & -42.10 \\ 36 & 190.00 & -251.00 & -58.20 \\ 37 & 215.00 & -190.00 & -50.50 \\ 38 & 241.00 & -139.00 & -45.90 \\ 39 & 265.00 & -92.10 & -64.90 \\ 40 & 288.00 & -51.70 & -49.60 \\ 41 & 315.00 & -14.70 & -39.20 \\ 42 & 344.00 & 18.50 & -33.80 \\ 43 & 371.00 & 48.00 & -46.30 \\ 44 & 388.00 & 75.50 & -77.40 \\ 45 & 393.00 & 98.40 & -86.50 \\ 46 & 392.00 & 116.00 & -100.00 \\ 47 & 378.00 & 131.00 & -138.00 \\ 48 & 350.00 & 143.00 & -141.00 \\ 49 & 316.00 & 152.00 & -150.00 \\ 50 & 272.00 & 158.00 & -173.00 \\ 51 & 216.00 & 158.00 & -199.00 \\ 52 & 145.00 & 158.00 & -238.00 \\ 53 & 23.80 & 175.00 & 127.00 \\ 54 & 0.00 & 281.00 & 891.00 \\ 55 & 0.00 & 269.00 & 371.00 \\ 56 & 32.80 & 325.00 & 138.00 \\ 57 & 137.00 & 446.00 & 107.00 \\ 58 & 274.00 & 404.00 & 140.00 \\ 59 & 409.00 & 671.00 & 103.00 \\ 60 & 497.00 & 672.00 & 45.50 \\ 61 & 544.00 & 665.00 & 9.68 \\ 62 & 562.00 & 665.00 & -28.00 \\ 63 & 550.00 & 674.00 & -85.50 \\ 64 & 512.00 & 687.00 & -102.00\end{array}$

\section{Inner Radius Bearing Connection}

The bearing stress on the inner radius weld bars has been calculated and is shown in the table below. A 5mm wide bearing area of the weld bar is used in this calculation. The force P1, which is the force per unit length, given above, was used in this calculation. 
Front Plate Bearing Stress (MPa)

\begin{tabular}{|c|c|c|c|}
\hline Module \# & Front & Middle & Back \\
\hline 2 & 136.00 & 70.80 & 78.00 \\
\hline 3 & 141.00 & 56.20 & 61.80 \\
\hline 4 & 152.20 & 39.80 & 42.40 \\
\hline 5 & 173.00 & 22.00 & 20.00 \\
\hline 6 & 222.00 & 7.56 & 0.58 \\
\hline 7 & 290.00 & 0.00 & 0.00 \\
\hline 8 & 352.00 & 0.00 & 0.00 \\
\hline 9 & 382.00 & 5.72 & 0.00 \\
\hline 10 & 438.00 & 37.20 & 3.70 \\
\hline 11 & 524.00 & 72.80 & 25.00 \\
\hline 12 & 156.60 & 104.40 & 55.60 \\
\hline 13 & 195.00 & 124.80 & 73.40 \\
\hline 14 & 222.00 & 139.40 & 89.40 \\
\hline 15 & 236.00 & 148.80 & 102.60 \\
\hline 16 & 238.00 & 153.20 & 112.60 \\
\hline 17 & 232.00 & 154.40 & 121.00 \\
\hline 18 & 222.00 & 152.60 & 127.60 \\
\hline 19 & 206.00 & 148.00 & 131.60 \\
\hline 20 & 186.80 & 140.40 & 132.40 \\
\hline 21 & 163.60 & 130.40 & 130.00 \\
\hline 22 & 139.20 & 118.80 & 126.00 \\
\hline 23 & 113.40 & 105.60 & 119.60 \\
\hline 24 & 87.40 & 91.40 & 111.40 \\
\hline 25 & 63.60 & 77.40 & 103.20 \\
\hline 26 & 43.00 & 63.60 & 95.20 \\
\hline 27 & 25.80 & 50.20 & 87.00 \\
\hline 28 & 11.92 & 37.00 & 77.60 \\
\hline 29 & 2.24 & 24.40 & 67.40 \\
\hline 30 & 0.00 & 13.10 & 58.00 \\
\hline 31 & 0.00 & 1.65 & 48.40 \\
\hline 32 & 0.00 & 0.00 & 31.60 \\
\hline 33 & 0.00 & 0.00 & 3.12 \\
\hline 34 & 0.00 & 0.00 & 0.00 \\
\hline 35 & 0.00 & 0.00 & 12.34 \\
\hline 36 & 0.00 & 0.00 & 38.00 \\
\hline 37 & 0.00 & 6.74 & 43.00 \\
\hline 38 & 0.46 & 14.46 & 48.20 \\
\hline 39 & 6.32 & 24.00 & 53.00 \\
\hline 40 & 16.90 & 34.60 & 57.60 \\
\hline
\end{tabular}

(P1/5mm) 
$11 / 07 / 2002$

$\begin{array}{lccc}41 & 32.80 & 46.80 & 63.00 \\ 42 & 52.20 & 59.80 & 68.80 \\ 43 & 74.20 & 73.20 & 74.20 \\ 44 & 95.80 & 86.00 & 77.60 \\ 45 & 116.20 & 97.80 & 78.60 \\ 46 & 135.60 & 109.20 & 78.40 \\ 47 & 151.40 & 119.00 & 75.60 \\ 48 & 162.00 & 127.20 & 70.00 \\ 49 & 167.20 & 134.00 & 63.20 \\ 50 & 163.20 & 138.40 & 54.40 \\ 51 & 145.40 & 139.80 & 43.20 \\ 52 & 109.60 & 136.60 & 29.00 \\ 53 & 536.00 & 123.80 & 4.76 \\ 54 & 452.00 & 113.40 & 0.00 \\ 55 & 396.00 & 110.80 & 0.00 \\ 56 & 366.00 & 115.20 & 6.56 \\ 57 & 342.00 & 122.60 & 27.40 \\ 58 & 298.00 & 126.60 & 54.80 \\ 59 & 250.00 & 127.40 & 81.80 \\ 60 & 214.00 & 125.40 & 99.40 \\ 61 & 187.20 & 121.00 & 108.80 \\ 62 & 167.80 & 114.80 & 112.40 \\ 63 & 153.40 & 106.40 & 110.00 \\ 64 & 142.40 & 95.80 & 102.40\end{array}$

The largest bearing stresses occur in the front of the EB in the modules that are directly below the cryostat load. These bearing stresses approach 536MPa in modules interface 53-54 and 11-12, which exceeds the ultimate stress of the weld bar material. An acceptable limit of the bearing stress is less than $240 \mathrm{MPa}$. Using this as a criteria, module interfaces 5-6, 6-7, 7-8, 8-9, 9-10, 10-11, 11-12 and 53-54, 54-55, 55-56, 56-57, 57-58, 58-59, 59-60 will need to have extra bearing material placed between the modules in order to distribute the bearing force at the inner radius onto the master plates.

Earlier tests on the ability of the front plate to withstand the bearing load at the inner radius have shown that plastic deformation of the front plate occurs when a bearing load of 38 tons is applied to a submodule $(1694 \mathrm{~N} / \mathrm{mm})$. Failure of the welds and the front plate occurred in these tests at a maximum load of 85 tons applied to three modules $(3,789 \mathrm{~N} / \mathrm{mm})$. In these tests the entire bearing load was transferred through the front plate. In the back and middle of the EB, no modules have a force P1, which exceeds the yield load. In the front of the EB, however, modules 9-10, 10-11, 11-12, 12-13 and 54-55, 55-56, 56-57, 57-58, 58-59 exceed the yield load. 


\section{Connections Between Modules at the Outer Radius}

The modules are connected together at their outer radius by a series of connecting plates. The details of this connection and the forces acting on it are shown in Fig. 1. M30 bolts and 33mm diameter pins must resist tension and shearing forces at the outer radius. At the bottom of the extended barrel, the bearing force, P2, results in tension between the modules. This is resisted by replacing a portion of the M30 bolts with 33mm diameter pins in modules 1-6 and 58-64. At the very top of the extended barrel, the bearing force, $\mathrm{P} 2$, is also tension, however, this is much smaller than at the bottom so it will be resisted by generating a friction force by the M30 bolts. In the remainder of the detector, the bearing force, $\mathrm{P} 2$, is compression and this is resisted by the bearing surface between the outer radiuses of the modules.

\subsection{Bearing Force at Outer Radius}

The bearing force at the outer radius, $\mathrm{P} 2$, is distributed over a $37.5 \mathrm{~mm}$ thick plate on the outer radius of the girder. Therefore, the bearing stress can be simply calculated as P $2 / 37.5 \mathrm{~mm}$ and is listed in the table below. The positions that are blank are in tension and the force P2 in those locations are carried by a $33 \mathrm{~mm}$ diameter pin below the saddle or friction above the saddle. It can be seen in the table below that the bearing stresses are all small and within acceptable limits.

\begin{tabular}{|c|c|c|c|}
\hline \multicolumn{4}{|c|}{ Bearing Stress and their location at the Outer Radius } \\
\hline Module \# & Front & Middle & Back \\
\hline 7 & -67.73 & -9.23 & Tension \\
\hline 8 & -53.87 & -11.57 & Tension \\
\hline 9 & -41.33 & -10.91 & Tension \\
\hline 10 & -30.93 & -8.45 & Tension \\
\hline 11 & -22.59 & -5.41 & Tension \\
\hline 12 & -16.61 & -2.93 & Tension \\
\hline 13 & -11.44 & -0.98 & Tension \\
\hline 14 & -7.31 & Tension & Tension \\
\hline 15 & -3.95 & Tension & Tension \\
\hline 16 & -1.22 & Tension & Tension \\
\hline 27 & Tension & Tension & -0.62 \\
\hline 28 & Tension & Tension & -1.71 \\
\hline 29 & Tension & Tension & -2.96 \\
\hline 30 & Tension & Tension & -4.40 \\
\hline 31 & Tension & Tension & -5.97 \\
\hline 32 & Tension & Tension & -7.81 \\
\hline 33 & Tension & Tension & -9.33 \\
\hline 34 & Tension & Tension & -9.36 \\
\hline 35 & Tension & Tension & -8.48 \\
\hline
\end{tabular}


$11 / 07 / 2002$

\begin{tabular}{l|ccc}
36 & Tension & Tension & -6.69 \\
37 & Tension & Tension & -5.07 \\
38 & Tension & Tension & -3.71 \\
39 & Tension & Tension & -2.46 \\
40 & Tension & Tension & -1.38 \\
41 & Tension & Tension & -0.39 \\
49 & -1.11 & Tension & Tension \\
50 & -3.65 & Tension & Tension \\
51 & -6.88 & Tension & Tension \\
52 & -10.99 & -0.54 & Tension \\
53 & -17.25 & -2.39 & Tension \\
54 & -21.44 & -3.41 & Tension \\
55 & -24.83 & -2.85 & Tension \\
56 & -30.93 & -1.00 & Tension \\
57 & -42.93 & Tension & Tension
\end{tabular}

\subsection{Tension Connection at the Outer Radius}

The tension force, $\mathrm{P} 2$, at the outer radius will be carried by $33 \mathrm{~mm}$ diameter pins in the modules below the saddle (module \#'s 1-6 and 58-64) and by friction throughout the remainder of the EB.

The length of the module that a given set of 2 pins carries the force is $350 \mathrm{~mm}$.

According to EUROCODE 3, chapter 6.5, the maximum design load on the pin connection is the minimal of

$$
\begin{aligned}
& F v=\frac{0.6 \bullet f u r \bullet A}{y M r} \\
& F b=\frac{2.5 \bullet a \bullet f u \bullet d o \bullet t}{y M r}
\end{aligned}
$$

where

$$
\begin{aligned}
& \mathrm{A}=\text { pin section } \\
& \mathrm{Fv}=\text { shear resistance per shear plane } \\
& \text { fur = ultimate tensile strength of the pin } \\
& \mathrm{yMr}=\text { safety factor }(1.25) \\
& \mathrm{Fb}=\text { Bearing resistance } \\
& \mathrm{fu}=\text { ultimate tensile strength of the basis material } \\
& \text { do = diameter of the pin hole }
\end{aligned}
$$


$\mathrm{t}=$ plate thickness

$\mathrm{a}=$ parameter (see ENV 1993-1-1, p.156)

Applying the above-mentioned formulas, we get the values:

$$
\mathrm{Fv}=492 \mathrm{KN} ; \mathrm{Fb}=355 \mathrm{kN} \text {. }
$$

Thus, the design load per pin is $355 \mathrm{kN}$. A set of pins is $710 \mathrm{kN}$, which is equivalent to 2,028 $\mathrm{N} / \mathrm{mm}(710 \mathrm{kN} / 350 \mathrm{~mm})$. The force P2 is below this value everywhere except at the front at modules interface 58-59 and 59-60, which have the values of 2,520 N/mm and $2330 \mathrm{~N} / \mathrm{mm}$, respectively.

\subsection{Tension Connection Carried by Friction}

In modules \#7 to 57, the tension force at the outer radius, $\mathrm{P} 2$, is carried by friction. The maximum tension force in these modules occurs at the front of module \#33 and is $597 \mathrm{~N} / \mathrm{mm}$. Using a coefficient of friction of .2, a normal force of $2,985 \mathrm{~N} / \mathrm{mm}$ can be calculated to be needed for this friction force. There are two bolts for every $175 \mathrm{~mm}$ of length, so the normal force per bolt is

$$
\text { Fbolt }=[(2,985 \mathrm{~N} / \mathrm{mm}) * 175 \mathrm{~mm}] / 2=261 \mathrm{kN} .
$$

The resulting normal force in the bolt is Fbolt / Area $=261 \mathrm{kN} / 539 \mathrm{~mm}^{2}=484 \mathrm{MPa}$. Using a safety factor of 1.5 yields a pre-stress of 726 . Therefore, a pre-stress must be applied to every bolt of $726 \mathrm{MPa}$ in order to achieve the required friction force.

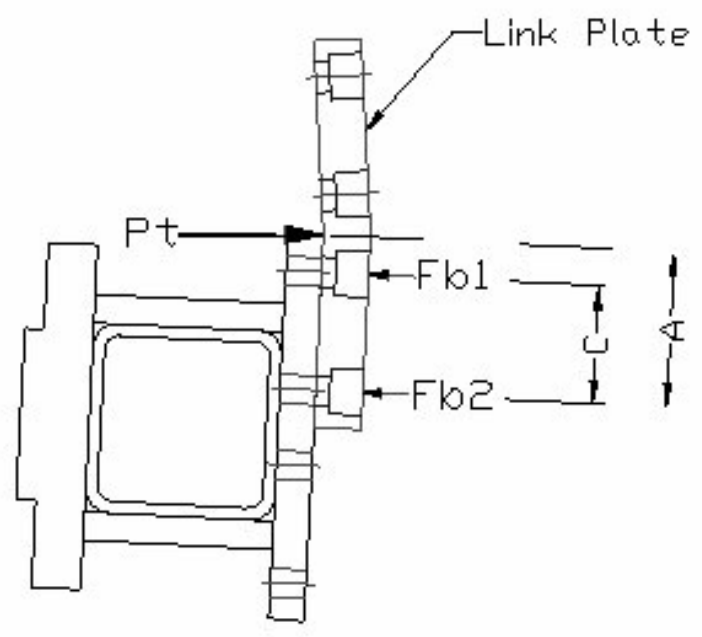

Figure 1. Forces Acting on Connecting Plate. 


\subsection{Calculation of the Girder/Link Plate Bolt Stresses}

At a given connection between modules, the force, Pt, is resisted as shown in Fig. 1. Solving for the forces on the bolts we find

$$
\begin{aligned}
& F_{b 1}=\frac{P_{t} \bullet L \bullet A}{C} \\
& F_{b 2}=\left(P_{t} \bullet L\right) \bullet\left(1-\frac{A}{C}\right) \\
& \mathrm{A}=165 \mathrm{~mm} \\
& \mathrm{C}=125 \mathrm{~mm}
\end{aligned}
$$

$\mathrm{Pt}$ is a force distributed over the length of the module in $\mathrm{Z}$. $\mathrm{L}$ is the length of the module that a given bolt is acting upon, on average; this is one bolt per $175 \mathrm{~mm}$ in modules $7-57$ and $350 \mathrm{~mm}$ in modules 1-6 and 58-64.

Link Plate Bolt Forces (N)

\begin{tabular}{|c|c|c|c|c|c|c|}
\hline & \multicolumn{3}{|c|}{ Fb1 } & \multicolumn{3}{c|}{ Fb2 } \\
\hline Module \# & Front & Middle & Back & Front & Middle & Back \\
\hline 2 & $-151,200$ & $-106,704$ & $-54,864$ & 39,200 & 27,664 & 14,224 \\
\hline 3 & $-156,384$ & $-111,024$ & $-62,208$ & 40,544 & 28,784 & 16,128 \\
\hline 4 & $-171,072$ & $-121,392$ & $-73,008$ & 44,352 & 31,472 & 18,928 \\
\hline 5 & $-174,096$ & $-116,208$ & $-69,552$ & 45,136 & 30,128 & 18,032 \\
\hline 6 & 210,816 & $-7,128$ & $-101,952$ & $-54,656$ & 1,848 & 26,432 \\
\hline 7 & $-39,501$ & -901 & $-55,440$ & 9,576 & 218 & 13,440 \\
\hline 8 & 180,180 & 95,403 & $-75,306$ & $-43,680$ & $-23,128$ & 18,256 \\
\hline 9 & 286,440 & 163,086 & $-83,622$ & $-69,440$ & $-39,536$ & 20,272 \\
\hline 10 & 371,910 & 211,827 & $-34,419$ & $-90,160$ & $-51,352$ & 8,344 \\
\hline 11 & 385,770 & 209,517 & 10,603 & $-93,520$ & $-50,792$ & $-2,570$ \\
\hline 12 & 172,788 & 137,676 & 87,318 & $-41,888$ & $-33,376$ & $-21,168$ \\
\hline 13 & 129,360 & 112,035 & 81,543 & $-31,360$ & $-27,160$ & $-19,768$ \\
\hline 14 & 90,321 & 87,318 & 74,151 & $-21,896$ & $-21,168$ & $-17,976$ \\
\hline 15 & 48,048 & 57,519 & 60,984 & $-11,648$ & $-13,944$ & $-14,784$ \\
\hline 16 & 17,556 & 39,039 & 55,902 & $-4,256$ & $-9,464$ & $-13,552$ \\
\hline 17 & $-10,118$ & 21,183 & 50,127 & 2,453 & $-5,135$ & $-12,152$ \\
\hline 18 & $-33,957$ & 5,313 & 44,121 & 8,232 & $-1,288$ & $-10,696$ \\
\hline 19 & $-56,826$ & $-12,012$ & 34,650 & 13,776 & 2,912 & $-8,400$ \\
\hline 20 & $-80,388$ & $-31,416$ & 21,830 & 19,488 & 7,616 & $-5,292$ \\
\hline 21 & $-94,248$ & $-42,042$ & 15,408 & 22,848 & 10,192 & $-3,735$ \\
\hline 22 & $-103,488$ & $-50,127$ & 9,125 & 25,088 & 12,152 & $-2,212$ \\
\hline 23 & $-114,807$ & $-62,139$ & $-1,499$ & 27,832 & 15,064 & 363 \\
\hline
\end{tabular}




\begin{tabular}{|c|c|c|c|c|c|c|}
\hline 24 & $-113,883$ & $-62,139$ & $-2,911$ & 27,608 & 15,064 & 706 \\
\hline 25 & $-110,187$ & $-60,753$ & $-4,135$ & 26,712 & 14,728 & 1,002 \\
\hline 26 & $-103,026$ & $-57,288$ & $-5,105$ & 24,976 & 13,888 & 1,238 \\
\hline 27 & $-95,865$ & $-55,671$ & $-8,824$ & 23,240 & 13,496 & 2,139 \\
\hline 28 & $-90,552$ & $-56,595$ & $-15,454$ & 21,952 & 13,720 & 3,746 \\
\hline 29 & $-77,385$ & $-49,203$ & $-15,662$ & 18,760 & 11,928 & 3,797 \\
\hline 30 & $-61,677$ & $-41,118$ & $-15,754$ & 14,952 & 9,968 & 3,819 \\
\hline 31 & $-50,358$ & $-37,884$ & $-20,420$ & 12,208 & 9,184 & 4,950 \\
\hline 32 & $-29,799$ & $-24,255$ & $-16,239$ & 7,224 & 5,880 & 3,937 \\
\hline 33 & $-8,940$ & $-11,365$ & $-12,520$ & 2,167 & 2,755 & 3,035 \\
\hline 34 & 12,035 & 1,495 & $-9,402$ & $-2,918$ & -362 & 2,279 \\
\hline 35 & 29,337 & 10,511 & $-9,725$ & $-7,112$ & $-2,548$ & 2,358 \\
\hline 36 & 41,118 & 14,507 & $-13,444$ & $-9,968$ & $-3,517$ & 3,259 \\
\hline 37 & 57,288 & 24,255 & $-11,666$ & $-13,888$ & $-5,880$ & 2,828 \\
\hline 38 & 72,072 & 32,802 & $-10,603$ & $-17,472$ & $-7,952$ & 2,570 \\
\hline 39 & 78,771 & 33,726 & $-14,992$ & $-19,096$ & $-8,176$ & 3,634 \\
\hline 40 & 91,245 & 42,504 & $-11,458$ & $-22,120$ & $-10,304$ & 2,778 \\
\hline 41 & 100,023 & 48,279 & $-9,055$ & $-24,248$ & $-11,704$ & 2,195 \\
\hline 42 & 105,567 & 51,975 & $-7,808$ & $-25,592$ & $-12,600$ & 1,893 \\
\hline 43 & 104,643 & 49,896 & $-10,695$ & $-25,368$ & $-12,096$ & 2,593 \\
\hline 44 & 95,172 & 40,656 & $-17,879$ & $-23,072$ & $-9,856$ & 4,334 \\
\hline 45 & 87,549 & 35,805 & $-19,982$ & $-21,224$ & $-8,680$ & 4,844 \\
\hline 46 & 76,461 & 28,413 & $-23,100$ & $-18,536$ & $-6,888$ & 5,600 \\
\hline 47 & 55,209 & 12,058 & $-31,878$ & $-13,384$ & $-2,923$ & 7,728 \\
\hline 48 & 38,346 & 2,980 & $-32,571$ & $-9,296$ & -722 & 7,896 \\
\hline 49 & 16,886 & $-9,633$ & $-34,650$ & $-4,094$ & 2,335 & 8,400 \\
\hline 50 & $-11,758$ & $-27,720$ & $-39,963$ & 2,850 & 6,720 & 9,688 \\
\hline 51 & $-43,890$ & $-48,048$ & $-45,969$ & 10,640 & 11,648 & 11,144 \\
\hline 52 & $-85,239$ & $-74,844$ & $-54,978$ & 20,664 & 18,144 & 13,328 \\
\hline 53 & $-244,860$ & $-116,193$ & 29,337 & 59,360 & 28,168 & $-7,112$ \\
\hline 54 & $-196,119$ & $-67,914$ & 205,821 & 47,544 & 16,464 & $-49,896$ \\
\hline 55 & $-25,410$ & $-21,830$ & 85,701 & 6,160 & 5,292 & $-20,776$ \\
\hline 56 & 105,336 & 12,243 & 31,878 & $-25,536$ & $-2,968$ & $-7,728$ \\
\hline 57 & $-5,013$ & $-3,604$ & 24,717 & 1,215 & 874 & $-5,992$ \\
\hline 58 & $-189,216$ & $-47,952$ & 60,480 & 49,056 & 12,432 & $-15,680$ \\
\hline 59 & $-162,432$ & $-66,960$ & 44,496 & 42,112 & 17,360 & $-11,536$ \\
\hline 60 & $-165,888$ & $-81,648$ & 19,656 & 43,008 & 21,168 & $-5,096$ \\
\hline 61 & $-160,272$ & $-84,672$ & 4,182 & 41,552 & 21,952 & $-1,084$ \\
\hline 62 & $-155,520$ & $-89,856$ & $-12,096$ & 40,320 & 23,296 & 3,136 \\
\hline 63 & $-163,296$ & $-107,136$ & $-36,936$ & 42,336 & 27,776 & 9,576 \\
\hline 64 & $-156,816$ & $-106,272$ & $-44,064$ & 40,656 & 27,552 & 11,424 \\
\hline
\end{tabular}

The stress in the bolts is 


$$
\begin{aligned}
& \sigma=\frac{F}{A} \\
& \mathrm{~F}=\text { bolt force }(\mathrm{Fb} 1 \text { or } \mathrm{Fb} 2) \text { increased by } 25 \% \text { per Eurocode } \\
& \mathrm{A}=\text { area of bolt }=539 \mathrm{~mm}^{2}
\end{aligned}
$$

The bolt normal stresses are shown in the table below.

Normal Stress in M30 bolts (MPa)

(Bolt Force increased by $25 \%$ per Eurocode)

\begin{tabular}{|c|c|c|c|c|c|c|}
\hline $\begin{array}{c}\text { Module } \\
\#\end{array}$ & Front & Middle & Back & Front & Middlle & Back \\
\hline 2 & -350.65 & -247.46 & -127.24 & 90.91 & 64.16 & 32.99 \\
\hline 3 & -362.67 & -257.48 & -144.27 & 94.03 & 66.75 & 37.40 \\
\hline 4 & -396.73 & -281.52 & -169.31 & 102.86 & 72.99 & 43.90 \\
\hline 5 & -403.75 & -269.50 & -161.30 & 104.68 & 69.87 & 41.82 \\
\hline 6 & 488.91 & -16.53 & -236.44 & -126.75 & 4.29 & 61.30 \\
\hline 7 & -91.61 & -2.09 & -128.57 & 22.21 & 0.51 & 31.17 \\
\hline 8 & 417.86 & 221.25 & -174.64 & -101.30 & -53.64 & 42.34 \\
\hline 9 & 664.29 & 378.21 & -193.93 & -161.04 & -91.69 & 47.01 \\
\hline 10 & 862.50 & 491.25 & -79.82 & -209.09 & -119.09 & 19.35 \\
\hline 11 & 894.64 & 485.89 & 24.59 & -216.88 & -117.79 & -5.96 \\
\hline 12 & 400.71 & 319.29 & 202.50 & -97.14 & -77.40 & -49.09 \\
\hline 13 & 300.00 & 259.82 & 189.11 & -72.73 & -62.99 & -45.84 \\
\hline 14 & 209.46 & 202.50 & 171.96 & -50.78 & -49.09 & -41.69 \\
\hline 15 & 111.43 & 133.39 & 141.43 & -27.01 & -32.34 & -34.29 \\
\hline 16 & 40.71 & 90.54 & 129.64 & -9.87 & -21.95 & -31.43 \\
\hline 17 & -23.46 & 49.13 & 116.25 & 5.69 & -11.91 & -28.18 \\
\hline 18 & -78.75 & 12.32 & 102.32 & 19.09 & -2.99 & -24.81 \\
\hline 19 & -131.79 & -27.86 & 80.36 & 31.95 & 6.75 & -19.48 \\
\hline 20 & -186.43 & -72.86 & 50.63 & 45.19 & 17.66 & -12.27 \\
\hline 21 & -218.57 & -97.50 & 35.73 & 52.99 & 23.64 & -8.66 \\
\hline 22 & -240.00 & -116.25 & 21.16 & 58.18 & 28.18 & -5.13 \\
\hline 23 & -266.25 & -144.11 & -3.48 & 64.55 & 34.94 & 0.84 \\
\hline 24 & -264.11 & -144.11 & -6.75 & 64.03 & 34.94 & 1.64 \\
\hline 25 & -255.54 & -140.89 & -9.59 & 61.95 & 34.16 & 2.32 \\
\hline 26 & -238.93 & -132.86 & -11.84 & 57.92 & 32.21 & 2.87 \\
\hline 27 & -222.32 & -129.11 & -20.46 & 53.90 & 31.30 & 4.96 \\
\hline 28 & -210.00 & -131.25 & -35.84 & 50.91 & 31.82 & 8.69 \\
\hline 29 & -179.46 & -114.11 & -36.32 & 43.51 & 27.66 & 8.81 \\
\hline 30 & -143.04 & -95.36 & -36.54 & 34.68 & 23.12 & 8.86 \\
\hline 31 & -116.79 & -87.86 & -47.36 & 28.31 & 21.30 & 11.48 \\
\hline 32 & -69.11 & -56.25 & -37.66 & 16.75 & 13.64 & 9.13 \\
\hline 33 & -20.73 & -26.36 & -29.04 & 5.03 & 6.39 & 7.04 \\
\hline 34 & 27.91 & 3.47 & -21.80 & -6.77 & -0.84 & 5.29 \\
\hline & & & & & & \\
\hline
\end{tabular}




\begin{tabular}{|c|c|c|c|c|c|c|}
\hline 35 & 68.04 & 24.38 & -22.55 & -16.49 & -5.91 & 5.47 \\
\hline 36 & 95.36 & 33.64 & -31.18 & -23.12 & -8.16 & 7.56 \\
\hline 37 & 132.86 & 56.25 & -27.05 & -32.21 & -13.64 & 6.56 \\
\hline 38 & 167.14 & 76.07 & -24.59 & -40.52 & -18.44 & 5.96 \\
\hline 39 & 182.68 & 78.21 & -34.77 & -44.29 & -18.96 & 8.43 \\
\hline 40 & 211.61 & 98.57 & -26.57 & -51.30 & -23.90 & 6.44 \\
\hline 41 & 231.96 & 111.96 & -21.00 & -56.23 & -27.14 & 5.09 \\
\hline 42 & 244.82 & 120.54 & -18.11 & -59.35 & -29.22 & 4.39 \\
\hline 43 & 242.68 & 115.71 & -24.80 & -58.83 & -28.05 & 6.01 \\
\hline 44 & 220.71 & 94.29 & -41.46 & -53.51 & -22.86 & 10.05 \\
\hline 45 & 203.04 & 83.04 & -46.34 & -49.22 & -20.13 & 11.23 \\
\hline 46 & 177.32 & 65.89 & -53.57 & -42.99 & -15.97 & 12.99 \\
\hline 47 & 128.04 & 27.96 & -73.93 & -31.04 & -6.78 & 17.92 \\
\hline 48 & 88.93 & 6.91 & -75.54 & -21.56 & -1.68 & 18.31 \\
\hline 49 & 39.16 & -22.34 & -80.36 & -9.49 & 5.42 & 19.48 \\
\hline 50 & -27.27 & -64.29 & -92.68 & 6.61 & 15.58 & 22.47 \\
\hline 51 & -101.79 & -111.43 & -106.61 & 24.68 & 27.01 & 25.84 \\
\hline 52 & -197.68 & -173.57 & -127.50 & 47.92 & 42.08 & 30.91 \\
\hline 53 & -567.86 & -269.46 & 68.04 & 137.66 & 65.32 & -16.49 \\
\hline 54 & -454.82 & -157.50 & 477.32 & 110.26 & 38.18 & -115.71 \\
\hline 55 & -58.93 & -50.63 & 198.75 & 14.29 & 12.27 & -48.18 \\
\hline 56 & 244.29 & 28.39 & 73.93 & -59.22 & -6.88 & -17.92 \\
\hline 57 & -11.63 & -8.36 & 57.32 & 2.82 & 2.03 & -13.90 \\
\hline 58 & -438.81 & -111.21 & 140.26 & 113.77 & 28.83 & -36.36 \\
\hline 59 & -376.70 & -155.29 & 103.19 & 97.66 & 40.26 & -26.75 \\
\hline 60 & -384.71 & -189.35 & 45.58 & 99.74 & 49.09 & -11.82 \\
\hline 61 & -371.69 & -196.36 & 9.70 & 96.36 & 50.91 & -2.51 \\
\hline 62 & -360.67 & -208.39 & -28.05 & 93.51 & 54.03 & 7.27 \\
\hline 63 & -378.70 & -248.46 & -85.66 & 98.18 & 64.42 & 22.21 \\
\hline 64 & -363.67 & -246.46 & -102.19 & 94.29 & 63.90 & 26.49 \\
\hline & & & & & & \\
\hline
\end{tabular}

A M30 class 10.4 bolt will be used, which has a yield stress of $1,000 \mathrm{~N} / \mathrm{mm}^{2}$. The maximum normal stress occurs in the front part of Module \#11 on bolt Fb1 and is $894 \mathrm{MPa}$. This is below the yield stress of the class 10.4 bolt, so all of the normal stresses on the bolts are within acceptable limits.

It had been planned to apply a pre-stress of $726 \mathrm{~N} / \mathrm{mm} 2$ to the M30 bolts on the link plates in order to achieve the required friction force. A pre-stress of $726 \mathrm{~N} / \mathrm{mm}^{2}$ would give an additional safety factor of 1.72 (a safety factor of 1.25 per Eurode is already applied) on all of the bolts. This is an adequate pre-stress on all of the modules except at the front of module interfaces $10-11,11-12$, and by symmetry module interfaces $54-55,55-56$, which have normal stresses that exceed $726 \mathrm{~N} / \mathrm{mm}^{2}$. In these special cases, a pre-stress of $894 \mathrm{~N} / \mathrm{mm}^{2}$ will be applied, which equals the maximum expected normal stress.

The shear stress of the internal threads of the bolted connection is calculated by 


$$
\tau=\frac{F}{A}
$$

$\mathrm{F}=$ bolt force $(\mathrm{Fb} 1$ or $\mathrm{Fb} 2)$ increased by $25 \%$ per Eurocode
$\mathrm{A}=.87 *$ pi $* \mathrm{D} * \mathrm{~L}=2,849 \mathrm{~mm}^{\wedge} 2$
$\mathrm{D}=$ minor diameter of the thread $=27.8 \mathrm{~mm}$
$\mathrm{L}=$ length of engagement $=37.5 \mathrm{~mm}$

The shears stresses on the internal threads are shown in the table below.

Internal Thread Shear Stress (MPa)

(Bolt Force increased by $25 \%$ per Eurocode)

\begin{tabular}{|c|c|c|c|c|c|c|}
\hline & \multicolumn{3}{|c|}{ Fb1 } & \multicolumn{3}{|c|}{ Fb2 } \\
\hline Module \# & Front & Middle & Back & Front & Middle & Back \\
\hline 2 & -66.34 & -46.82 & -24.07 & 17.20 & 12.14 & 6.24 \\
\hline 3 & -68.61 & -48.71 & -27.29 & 17.79 & 12.63 & 7.08 \\
\hline 4 & -75.06 & -53.26 & -32.03 & 19.46 & 13.81 & 8.30 \\
\hline 5 & -76.38 & -50.99 & -30.52 & 19.80 & 13.22 & 7.91 \\
\hline 6 & 92.50 & -3.13 & -44.73 & -23.98 & 0.81 & 11.60 \\
\hline 7 & -17.33 & -0.40 & -24.32 & 4.20 & 0.10 & 5.90 \\
\hline 8 & 79.05 & 41.86 & -33.04 & -19.16 & -10.15 & 8.01 \\
\hline 9 & 125.68 & 71.55 & -36.69 & -30.47 & -17.35 & 8.89 \\
\hline 10 & 163.18 & 92.94 & -15.10 & -39.56 & -22.53 & 3.66 \\
\hline 11 & 169.26 & 91.93 & 4.65 & -41.03 & -22.29 & -1.13 \\
\hline 12 & 75.81 & 60.41 & 38.31 & -18.38 & -14.64 & -9.29 \\
\hline 13 & 56.76 & 49.16 & 35.78 & -13.76 & -11.92 & -8.67 \\
\hline 14 & 39.63 & 38.31 & 32.53 & -9.61 & -9.29 & -7.89 \\
\hline 15 & 21.08 & 25.24 & 26.76 & -5.11 & -6.12 & -6.49 \\
\hline 16 & 7.70 & 17.13 & 24.53 & -1.87 & -4.15 & -5.95 \\
\hline 17 & -4.44 & 9.29 & 21.99 & 1.08 & -2.25 & -5.33 \\
\hline 18 & -14.90 & 2.33 & 19.36 & 3.61 & -0.57 & -4.69 \\
\hline 19 & -24.93 & -5.27 & 15.20 & 6.04 & 1.28 & -3.69 \\
\hline 20 & -35.27 & -13.78 & 9.58 & 8.55 & 3.34 & -2.32 \\
\hline 21 & -41.35 & -18.45 & 6.76 & 10.02 & 4.47 & -1.64 \\
\hline 22 & -45.41 & -21.99 & 4.00 & 11.01 & 5.33 & -0.97 \\
\hline 23 & -50.37 & -27.26 & -0.66 & 12.21 & 6.61 & 0.16 \\
\hline 24 & -49.97 & -27.26 & -1.28 & 12.11 & 6.61 & 0.31 \\
\hline 25 & -48.34 & -26.66 & -1.81 & 11.72 & 6.46 & 0.44 \\
\hline 26 & -45.20 & -25.14 & -2.24 & 10.96 & 6.09 & 0.54 \\
\hline 27 & -42.06 & -24.43 & -3.87 & 10.20 & 5.92 & 0.94 \\
\hline 28 & -39.73 & -24.83 & -6.78 & 9.63 & 6.02 & 1.64 \\
\hline 29 & -33.95 & -21.59 & -6.87 & 8.23 & 5.23 & 1.67 \\
\hline 30 & -27.06 & -18.04 & -6.91 & 6.56 & 4.37 & 1.68 \\
\hline 31 & -22.09 & -16.62 & -8.96 & 5.36 & 4.03 & 2.17 \\
\hline 32 & -13.07 & -10.64 & -7.13 & 3.17 & 2.58 & 1.73 \\
\hline & & & & & & \\
\hline
\end{tabular}




\begin{tabular}{|c|c|c|c|c|c|c|}
\hline 33 & -3.92 & -4.99 & -5.49 & 0.95 & 1.21 & 1.33 \\
\hline 34 & 5.28 & 0.66 & -4.13 & -1.28 & -0.16 & 1.00 \\
\hline 35 & 12.87 & 4.61 & -4.27 & -3.12 & -1.12 & 1.03 \\
\hline 36 & 18.04 & 6.36 & -5.90 & -4.37 & -1.54 & 1.43 \\
\hline 37 & 25.14 & 10.64 & -5.12 & -6.09 & -2.58 & 1.24 \\
\hline 38 & 31.62 & 14.39 & -4.65 & -7.67 & -3.49 & 1.13 \\
\hline 39 & 34.56 & 14.80 & -6.58 & -8.38 & -3.59 & 1.59 \\
\hline 40 & 40.03 & 18.65 & -5.03 & -9.71 & -4.52 & 1.22 \\
\hline 41 & 43.89 & 21.18 & -3.97 & -10.64 & -5.14 & 0.96 \\
\hline 42 & 46.32 & 22.80 & -3.43 & -11.23 & -5.53 & 0.83 \\
\hline 43 & 45.91 & 21.89 & -4.69 & -11.13 & -5.31 & 1.14 \\
\hline 44 & 41.76 & 17.84 & -7.84 & -10.12 & -4.32 & 1.90 \\
\hline 45 & 38.41 & 15.71 & -8.77 & -9.31 & -3.81 & 2.13 \\
\hline 46 & 33.55 & 12.47 & -10.14 & -8.13 & -3.02 & 2.46 \\
\hline 47 & 24.22 & 5.29 & -13.99 & -5.87 & -1.28 & 3.39 \\
\hline 48 & 16.82 & 1.31 & -14.29 & -4.08 & -0.32 & 3.46 \\
\hline 49 & 7.41 & -4.23 & -15.20 & -1.80 & 1.02 & 3.69 \\
\hline 50 & -5.16 & -12.16 & -17.53 & 1.25 & 2.95 & 4.25 \\
\hline 51 & -19.26 & -21.08 & -20.17 & 4.67 & 5.11 & 4.89 \\
\hline 52 & -37.40 & -32.84 & -24.12 & 9.07 & 7.96 & 5.85 \\
\hline 53 & -107.43 & -50.98 & 12.87 & 26.04 & 12.36 & -3.12 \\
\hline 54 & -86.05 & -29.80 & 90.30 & 20.86 & 7.22 & -21.89 \\
\hline 55 & -11.15 & -9.58 & 37.60 & 2.70 & 2.32 & -9.12 \\
\hline 56 & 46.22 & 5.37 & 13.99 & -11.20 & -1.30 & -3.39 \\
\hline 57 & -2.20 & -1.58 & 10.84 & 0.53 & 0.38 & -2.63 \\
\hline 58 & -83.02 & -21.04 & 26.54 & 21.52 & 5.45 & -6.88 \\
\hline 59 & -71.27 & -29.38 & 19.52 & 18.48 & 7.62 & -5.06 \\
\hline 60 & -72.78 & -35.82 & 8.62 & 18.87 & 9.29 & -2.24 \\
\hline 61 & -70.32 & -37.15 & 1.83 & 18.23 & 9.63 & -0.48 \\
\hline 62 & -68.23 & -39.42 & -5.31 & 17.69 & 10.22 & 1.38 \\
\hline 63 & -71.65 & -47.01 & -16.21 & 18.57 & 12.19 & 4.20 \\
\hline 64 & -68.80 & -46.63 & -19.33 & 17.84 & 12.09 & 5.01 \\
\hline & & & & & & \\
\hline
\end{tabular}

The maximum allowable shear stress in the girder material is $138 \mathrm{Mpa}$. This stress is exceeded at the front part of module interfaces 10-11, 11-12, and by symmetry module interfaces 54-55, 55-56, which have shears stresses of $163 \mathrm{Mpa}$ and $169 \mathrm{Mpa}$, respectively.

\section{Conclusion}

In general, the connections between modules are safe; however, there are several exceptions which must be addressed.

- There are 14 modules in which the bearing stress on the inner radius weld bars exceeds acceptable stresses. Additional bearing area between the modules will be needed.

- The loads on the front plate exceed the load limits found through very early experiments on a large number of modules. This would require that the bearing force at the inner 
radius be transferred between modules by placing shim material on the master plates between the modules.

- The stresses on the pins are within acceptable limits except on two modules where the pin loads exceed the maximum acceptable limits.

- A $726 \mathrm{MPa}$ pre-stress is required on the M30 link plate bolts in order to carry the tension force in the upper part of the EB in friction.

- The normal stresses in all of the M30 link plate bolts are within acceptable limits. However, on 4 modules the pre-stress will have to be $894 \mathrm{Mpa}$ rather than $726 \mathrm{MPa}$, because of the high loads on those modules, in order to prevent separation of the link plate from the girder.

- The shear stresses in the M30 link plate bolts are within acceptable limits except on 2 modules where the acceptable level of stress is exceeded in the front of the EB.

In order to address the minor problems encountered in the connections described above, the following steps should be taken during the assembly of the EB.

1. Front Plate Bearing Load: In order to reduce the bearing stress at the Inner Radius, the following module interfaces will have a $30 \mathrm{~mm}$-wide aluminum placed on the master plates to better distribute the inner radius force, P1. A 30mm-wide shim was chosen, because it is known from earlier tests that the load will not be evenly distributed over this area and it is felt that this is a sufficient width to reduce the bearing force. Whereas, the high bearing stresses occur in the front of the EB, the shim will be placed along the entire length of the EB in order to avoid problems of distributing the load between the Inner Radius weld bars and the shims on the master plates.

Module interfaces: $\quad$ 5-6

6-7

7-8

8-9

9-10

10-11

11-12

12-13

13-14

51-52

$52-53$

53-54

54-55

55-56

56-57

57-58

58-59

59-60 
2. Pin Stresses: The pin stresses are exceeded on 2 modules. This problem can be resolved by using $42 \mathrm{~mm}$ diameter pins on the front link plate in the following module interfaces:

3. Pre-Stress: A pre-stress of $726 \mathrm{Mpa}$ should be used on all modules except module interfaces 10-11, 11-12, 54-55, and 55-56, which should use a pre-stress of 894 .

4. M30 Thread Shear Stresses: The maximum allowable shear stresses in the M30 bolts are exceeded at the front of 4 modules. This problem can be resolved by replacing the M30 bolts with M36 bolts in the front link plates of the problem modules. This will require that the problem modules will have the current M30 tapped holes in the back of the girder drilled out and tapped in place for a M36 thread. Several machinists have been consulted and feel that, if the modules are laid horizontally and a magnetic based drill is used, the M30 holes can be drilled out and the M36 thread can be power tapped. The most the drill/tap would protrude into the fiber area of the girder is $12-15 \mathrm{~mm}$ and there is already this clearance between the fibers and the bottom of the girder. This solution would be required of the following module interfaces:

$10-11$

$11-12$

$54-55$

$55-56$ 